\title{
Dementia and Painting in Patients from Different Cultural Backgrounds
}

\author{
Akira Midorikawa $^{a, b}$ Toshio Fukutake ${ }^{c}$ Mitsuru Kawamura ${ }^{b}$ \\ a Department of Psychology, Chuo University Faculty of Letters, ${ }^{b}$ Department of Neurology, Showa University \\ School of Medicine, Tokyo, and ' Department of Neurology, Kameda Medical Center, Chiba, Japan
}

\section{Key Words}

Dementia - Frontotemporal lobar degeneration - Semantic dementia $\cdot$ Painting $\cdot$ Cultural differences

\begin{abstract}
Background/Aim: Some patients with frontotemporal lobar degeneration (FTLD) have been shown to develop painting abilities after the onset of the disease; however, the reported cases have all been in western countries. The purpose of this report was to investigate whether this phenomenon was unique to western countries. Methods: 2 patients participated in this study. They were nonwestern uneducated patients with FTLD, semantic dementia subtype, who developed drawing skills after the onset of the disease. We compared their drawings with drawings in previous reports. Results: The characteristics of their paintings matched those of paintings from previously reported cases despite the cultural differences. Conclusion: These results support the assumption that the appearance of painting skills during this illness is not a reflection of learning, but instead is an expression of innate functions of the brain.

Copyright $\odot 2008$ S. Karger AG, Basel
\end{abstract}

\section{Introduction}

Frontotemporal lobar degeneration (FTLD) refers to a group of conditions that present with primary dementia characterized by disproportionate atrophy of the anterior frontal and temporal lobes [1]. Although it is rare, in some cases, patients with FTLD have shown the development of painting abilities after the onset of their disease [2-4]. For patients who had experience with painting, their paintings changed in quality during the disease $[3,4]$. Patients who were not experienced painters not only started to paint after the onset of the disease, but also developed artistic skills [2]. However, most of reported cases were all in western countries, and few reports have described cases in nonwestern countries. To our knowledge, only 1 Japanese case study showed changes in painting quality with progression of the disease [5]. However, the patient was not a naive but a skilled painter before the illness. Like music, painting is influenced by education and cultural background. Therefore, it is important to examine whether FTLD influences artistic skills beyond the influence of culture. If the symptom is a common phenomenon across cultural boundaries, painting behavior might be a universal feature in humans.

Here, we present 2 cases of Japanese patients with FTLD, semantic dementia subtype, who did not have the habit of drawing but started painting after the onset of FTLD. It has been proposed that there are several subtypes of FTLD [6]; however, it is unclear whether these subtypes are reflected in the characteristics of the paintings. Thus, we also examined the possibility of a relationship between the disease subtypes and the characteristics of the paintings.

\section{KARGER \\ Fax +4161306 1234 E-Mail karger@karger.ch} www.karger.com

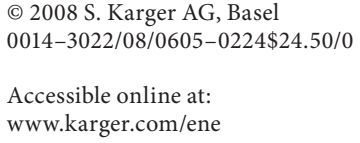

Akira Midorikawa

Department of Psychology

Chuo University Faculty of Letters

742-1 Higashi-nakano, Hachioji, Tokyo 192-0393 (Japan)

Tel./Fax +81 42674 3742, E-Mail green@tamacc.chuo-u.ac.jp 
Table 1. Neuropsychological profile

\begin{tabular}{|c|c|c|c|}
\hline & Case 1 & Case 2 & $\begin{array}{l}\text { Max. } \\
\text { score }\end{array}$ \\
\hline Hasegawa Dementia Scale-Revised & - & 16 & 30 \\
\hline Mini-Mental State Examination & - & 15 & 30 \\
\hline \multicolumn{4}{|c|}{ Wechsler Adult Intelligence Scale-Revised } \\
\hline Information & 2 & - & \\
\hline Digit span & 6 & - & \\
\hline Vocabulary & 4 & - & \\
\hline Arithmetic & 6 & - & \\
\hline Comprehension & 1 & - & \\
\hline Similarities & 2 & - & \\
\hline Verbal IQ & 58 & & \\
\hline Picture completion & 1 & 2 & \\
\hline Picture arrangement & 9 & 6 & \\
\hline Block design & 12 & 6 & \\
\hline Object assembly & 13 & 6 & \\
\hline Digit symbol & 7 & 10 & \\
\hline Performance IQ & 88 & 76 & \\
\hline Full-scale IQ & 69 & - & \\
\hline \multicolumn{4}{|l|}{ Raven Colored Progressive Matrices } \\
\hline Raw score & 31 & 28 & 36 \\
\hline \multicolumn{4}{|l|}{ Western Aphasia Battery } \\
\hline Spontaneous speech & 16.0 & - & 20 \\
\hline Comprehension & 6.8 & - & 10 \\
\hline Repetition & 5.6 & - & 10 \\
\hline Naming & 1.7 & - & 10 \\
\hline Reading & 4.0 & - & 10 \\
\hline Writing & 8.5 & - & 10 \\
\hline \multicolumn{4}{|l|}{ Standard Language Test for Aphasia } \\
\hline Comprehension & - & 33 & 40 \\
\hline Repetition (words) & - & 10 & 10 \\
\hline Naming & - & 5 & 20 \\
\hline Reading & - & 9 & 10 \\
\hline Writing & - & 4 & 10 \\
\hline \multicolumn{4}{|l|}{ Wisconsin Card Sorting Test } \\
\hline Category completed & 3 & - & 6 \\
\hline
\end{tabular}

\section{Case Reports}

\section{Case 1}

Case 1 involved a 53-year-old right-handed woman who was a part-time supermarket employee and owner of a snack bar. At the age of 49 , she noticed that she was having difficulty recalling the names of certain objects, which prompted her to visit a local clinic. She was prescribed donepezil hydrochloride at the clinic, but stopped taking the prescription because of side effects. In March 2004, at the age of 51, she visited Showa University Hospital because her verbal deficit was worsening. In addition to difficulty recalling the meanings of words, she showed several abnormal behaviors such as intrusiveness and repetitive actions. After the onset, she was still able to live independently and prepare food for her customers at the snack bar. Sometimes she took day-long trips by car, and she reported the details of the trips in few words. In June 2006, at the age of 53, her abnormal behavior became worse.
She forced her way into a neighbor's house and received reprimands from the police on several occasions. After that, her symptoms moderated and she showed no apparent problems, except for verbal deficits.

Neuropsychological examination (March 2004) showed a marked deficit in verbal functioning (table 1 ). She had a verbal IQ score of 58 and a performance IQ score of 88 on the Japanese version of the Wechsler Adult Intelligence Scale-Revised [7]. In the Raven Colored Progressive Matrices [8], she scored 31 points, which was within 2 SD of the age-matched control. Her frontal lobe function had also deteriorated; she scored 3 points on the Wisconsin Card Sorting Test [9]. In terms of verbal functioning, she showed preserved speech and comprehension ability, but had a severe naming deficit. In the object naming task, the initial sound cue did not help her performance. In contrast to the naming task, in the word fluency task (under the category of vegetable), she showed slightly preserved ability (5 words/min). As long as understandable words were used, she showed well-preserved comprehension ability. The examiner requested: 'Put the pencil on the book; after that, give me the pencil.' Thus, she could follow directions. Her reading disturbances, however, were more complex. When kana letters (Japanese phonograms) were presented, she could read easily, but she showed several errors in reading kanji (Japanese ideogram/Chinese characters). In the Japanese version of the Western Aphasia Battery [10], she showed apparent deterioration on the naming subscale (1.7/10 points); however, other verbal functions were relatively preserved (spontaneous speech, 16/20; comprehension, 6.8/10; repetition, 5.6/10; reading, $4 / 10$; writing, $8.5 / 10)$. Regarding praxis, she could not follow the instructions due to semantic deficits (11/30); however, imitation of praxis and usage of real objects were preserved (28/30 and $13 / 13$, respectively). Other subtests of the Western Aphasia Battery, such as drawing (25/30), block design (9/9) and calculation $(24 / 24)$ were also preserved. An example of her verbal deficit is as follows. The examiner asked: 'Do you eat a banana with the skin?' The patient responded: 'Banana? I don't know banana.' After a few seconds, the patient stated: 'I have not eaten banana ... I see, banana is yellow and ...' She then correctly represented the shape of a banana with a gesture. The examiner asked: 'Do you mow a lawn with an axe?', and the patient responded: 'Axe? ... Yes, I can't understand it.' Although we did not have the opportunity to conduct a memory test, it was indicated that she had well-preserved memory function. When we asked her the number of visits to our hospital, she could report the correct number. She could also remember the conversation at our previous interview (over 4 weeks earlier).

Magnetic resonance imaging (MRI) showed marked atrophy in the left temporal lobe (fig. 1a).

\section{Case 2}

Case 2 involved a 63-year-old right-handed man who was a farmer. He was admitted to a surgical unit with an esophageal tumor when he was 62 years old, and he received consultation from the neurological department for a memory problem; however, in the neuropsychological examination, a verbal deficit was also observed (table 1). In the dementia screening test (Hasegawa Dementia Scale-Revised [11]), he scored 16/30 points (cutoff, 20 points). The deterioration of the test score was attributable to a word-meaning deficit. For example, he failed the reversed digit task (subscale of the Hasegawa Dementia Scale-Revised) because 
he could not understand the meaning of 'backward' or 'counting in reverse.' During a clinical interview, it was noticed that he could not understand the meaning of the words 'wait', 'appetizer' or 'party'. In the Mini-Mental State Examination [12], he scored $15 / 30$ points. His orientation regarding the date and place were preserved (4/5 each); however, he could not name a pencil or watch. In the performance subscales of the Wechsler Adult Intelligence Scale-Revised, he showed below average scores, but the Raven Colored Progressive Matrices indicated preserved cognitive ability. In the Standard Language Test of Aphasia (standardized Japanese test for aphasia [13]), he showed severe difficulties with word retrieval and naming, even when the object was in front of him. He could not understand the meaning of 'animal', and thus could not perform the word fluency subtest of the Standard Language Test of Aphasia. In terms of writing ability, although he could not write kanji characters, he performed better in the kana writing test. In the Gogi (word meaning) aphasia battery [14], a marked deficit in kanji reading was observed (1/5), whereas kana reading was well preserved $(5 / 5)$, even when both letters represented the same meaning (table 2). In contrast to the patient in case 1 , he sometimes could not understand the meaning of objects. For example, with a drum, not only could he not name it, he also did not know what to do with it.

MRI showed marked atrophy of the left temporal lobe and slight enlargement of the ventricle (fig. 1b). In addition, several lacunar infarctions were observed in the white matter.

\section{Characteristics of Painting Activities}

The patients in cases 1 and 2 were not professional painters, and had no interest in drawing before the onset of FTLD. In both patients, drawing behavior was initiated by a physician or caregiver.

Patient 1 began to draw in response to a suggestion by her caregiver. She usually drew a picture from memory, drawing an object of her own selection. During the examination, the examiner presented only a theme to her. When the examiner asked about a short car trip that patient 1 had taken a few days prior to the examination, the patient drew objects that she had seen on the trip (fig. 2d). Every time she drew a picture, her drawing skill had improved. However, her drawing was not spontaneous. She started to draw only when we told her to draw a picture. The characteristics of the drawings were natural, and she could draw object details such as the veins or jagged edges of a leaf (fig. 2b). In addition, when she was provided with several color pencils, she drew objects using some colors on top of others. However, these drawing behaviors were limited to the examination situation; in daily situations, her natural behavior was observed while completing puzzles or singing karaoke. These behaviors were not present before the onset of FTLD. She usually completed a large puzzle $(>1,000$ pieces), representing flowers, of her own accord. Her behavior was characterized by a nonreferential and a non-trial-anderror method. She assembled a puzzle piece by piece, without looking at the sample picture, and she did not use any strategy, such as gathering by color or visualizing the completed picture. When she found the target piece in the scattered pieces, she reached for it and pieced it together without rotation. Her speech was usually restricted to a few words; nevertheless, she could fluently sing a song in a karaoke bar.

Patient 2 usually drew objects from real life or from pictures. When the model was hidden, he could not draw it. He drew a pic-
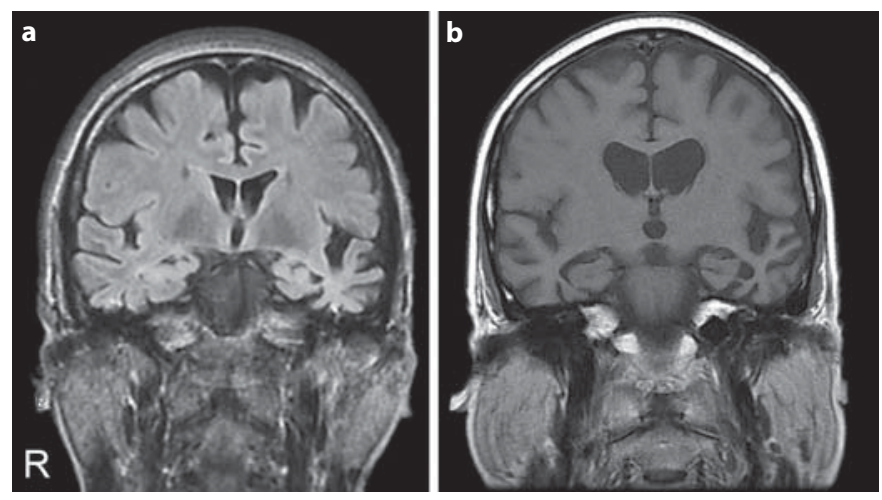

Fig. 1. $T_{1}$-weighted MRI scans. Both images show asymmetrical atrophy of the temporal lobe. a Case 1. b Case 2.

Table 2. The result of Gogi aphasia batteries in case 2 [14]

\begin{tabular}{ll}
\hline & Score $(\max .=5)$ \\
\hline Picture naming & 0 \\
Kanji reading & 1 \\
Pointing to a picture after kanji reading & 2 \\
Kana reading & 5 \\
\hline
\end{tabular}

ture only when a caregiver prompted him to draw a picture. Most of his drawings were based on real 3-dimensional objects, such as cars or flowers. He used color and copied the details of the objects. His paintings were also naturalistic in character (fig. 3).

\section{Discussion}

In the present study, the 2 Japanese patients with FTLD also had the following characteristics. First, the main common deficit in both was semantic dementia. Second, both patients developed drawing behavior after the onset of FTLD, despite not having been artists or having any interest in drawing before the illness. Third, the pictures drawn by both were realistic as opposed to abstract in character.

Although the emergence of artistic talent remains uncommon, several reports have presented patients demonstrating improvements in their artistic skills after the onset of FTLD. However, the patients in these cases had either been born in $[2,3]$ or been taught painting skills in a western country [4], or learned western styles before the onset [5]. Thus, the emergence of such painting skills after FTLD onset might have been influenced by cultural background or education. In contrast, our patients had a 
Fig. 2. Drawings in case 1 . These drawings are ordered by date. When we asked her to draw something, she drew blooming flowers in her garden from memory. When she could use several types of colored pencils, she drew a picture using 1 color over another [April 2004 (a), June 2004 (b)]. When we asked her to draw a tree, a subtest of the Western Aphasia Battery, she drew a piece of wood instead of a tree [June 2004 (c)]. Her memory was well preserved. When we asked to draw something concerning her short trip, she drew plants and vegetables, which were seen from a car window. In addition, when she could not use several colors, she drew a picture with shading [November $2004(\mathbf{d})$ ].

Fig. 3. Drawings in case 2. These drawings are ordered by date. Patient 2 drew realistic pictures from present objects rather than from memory, characteristically in 3 dimensions [March 2006 (a), August 2006 (b), November 2006 (c), January 2007 (d)].
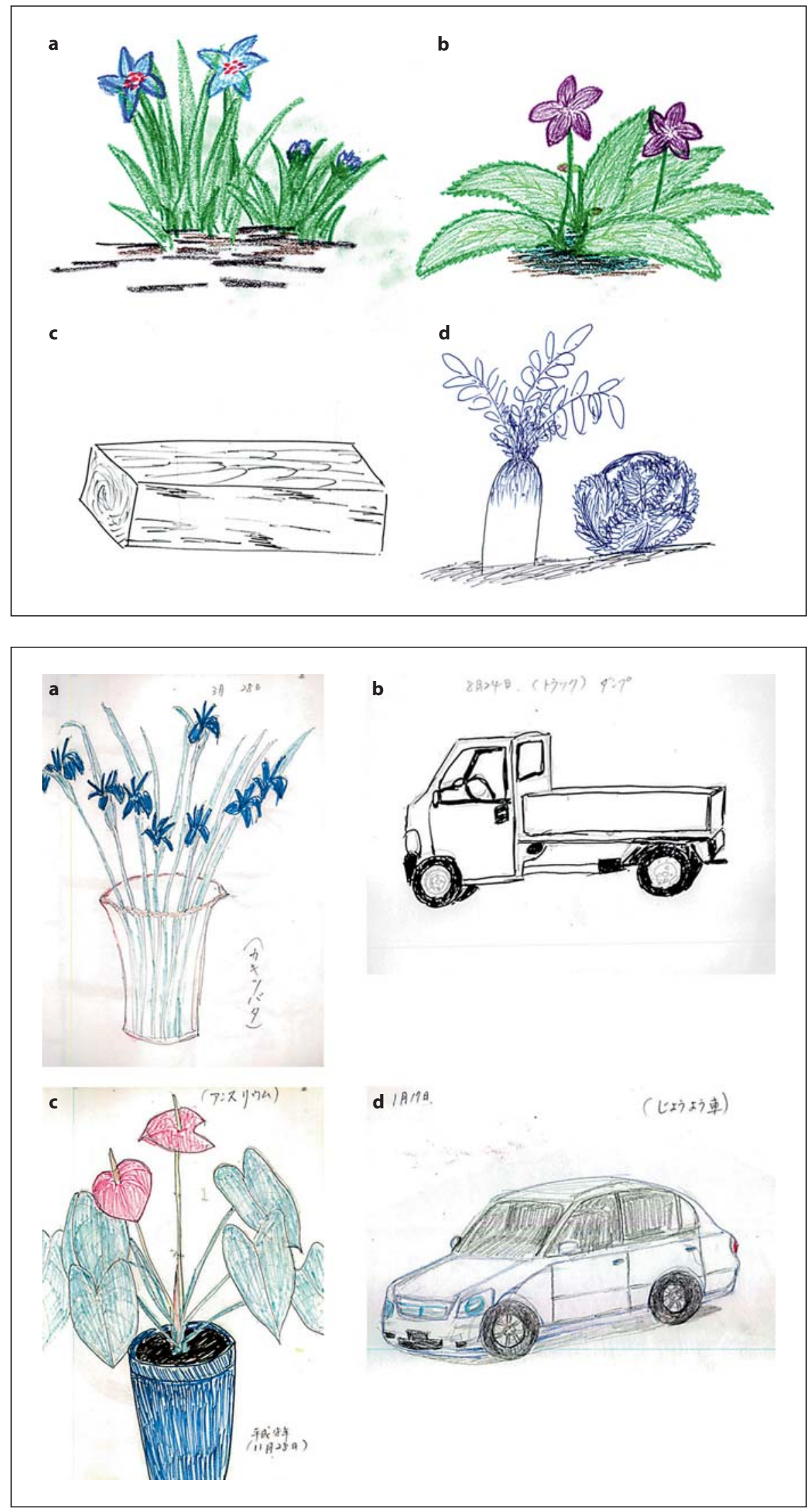
different cultural background and had not been previously educated in painting. The present results support the assumption that the appearance of painting skills during FTLD does not reflect learning or cultural background, but rather is the expression of innate functions of the brain. In addition, our patients' paintings were realistic in style, which might be an inherent phenomenon in humans, and not an advanced skill.

Miller et al. $[2,15]$ hypothesized that the emergence of artistic talent in patients with FTLD reflected paradoxical functional facilitation (PFF) effects. The original notion of PFF effects was proposed by Kapur [16, p. 1,776], and defined as a 'situation where alteration to intact neural tissues brings to normal or near-normal a level of functioning that was previously sub-normal or abnormal' and 'situations where a patient with a damaged nervous system can perform better than normal control subjects on a particular task'. The theoretical background of PFF was postulated as a disruption of inhibitory mechanisms or compensatory plasticity. Based on this hypothesis, Miller et al. [15, p. 462] assumed that degeneration of the left temporal cortex led to decreased inhibition of 'the right-sided and posteriorly located visual and musical systems'. On the other hand, Heilman et al. [17] proposed that reduced activity in frontal lobe functioning might be important for creative innovation. These 2 hypotheses were very attractive explanations of our patients' painting. However, we think that our patients' performance was not the result of improved artistic talent or creativity, but was instead a regression phenomenon. Our patients' paintings were of a realistic or 'slavish' style, depending on vivid imagery (case 1) or real objects (case 2). They painted details of the objects, such as veins on a leaf (fig. 2b, 3c). Considering the similarities between our patients and reported cases in which patients painted details of objects coming into sight [5], we think that the quality of their paintings was dependent on reduced verbal functioning, especially word-meaning deficits (selective loss of semantic memory for words [5]), which was characteristic of these patients.

Our hypothesis that diminished verbal functioning might be important for their painting quality is supported by studies on children with autism [18]. The most wellknown case of such a child with the ability to draw was Nadia [19]. She was born with a severe verbal deficit, but could draw several animals in a realistic style, even when she was of preschool age. After receiving training in verbal functioning, however, her drawing skills deteriorated. In contrast to dementia, the details of this child imply that realistic drawing is a natural innate style through which humans perceive the world in the absence of mature verbal function. A similar suggestion was made by Chatterjee [20], who argued that a similarity existed between semantic dementia and children with autism. Chatterjee [20] postulated that an impoverished conceptual representation of the world may actually help rendering what we see'. Based on this idea, we emphasize the importance of word meaning or semantic memory for words rather than a conceptual representation of the world or visual semantic ability [21]. We suggest that word meanings function as a filtering tool. When the subjects observed an apple, they were reminded of the notion of the object such as fruit, spherical or red, and they drew the object using these notions. However, when these notions were disturbed, as in our patients or in some children with autism, the subjects drew the object from direct representation. Thus, we suggest that a naturalistic style of drawing is an innate mechanism, independent of cultural influences. Additionally, the neuropsychological profile of our patient (case 1) shared similarities with children with autism. These children have been repeatedly reported to show good scores on the block design subscale in the Wechsler Intelligence Scale [22,23], and our patient (case 1) demonstrated a similar pattern. In addition, our patients showed good performance on a jigsaw puzzle, something persons with autism have also been reported to demonstrate [24]. Thus, the characteristics of painting in patients with FTLD and children with autism may arise from a common functional deficit.

There are 2 subtypes of aphasia in patients with FTLD, nonfluent aphasia and semantic aphasia. Our 2 patients had semantic aphasia, and their paintings were realistic. Although some patients with FTLD have produced creative work, our patients' pieces were not creative. The creative aspect might reflect the subtype of the disease. In fact, most of the reported drawings made by patients with FTLD with semantic aphasia were realistic in nature [2, 5], in contrast to the creative works produced by those with nonfluent aphasia $[3,4]$.

Our 2 patients exhibited difference characteristics in their paintings. While patient 1 could draw a picture from memory, patient 2 drew pictures of objects that were present. Regarding semantic memory, they had different characteristics. Patient 1 showed no apparent deficit in semantic memory for pictures. She could use real objects without hesitation and imagine the visual image of objects. In contrast, patient 2 showed possible global deficits in visualizing and understanding objects. For example, patient 2 had difficulty in using a drum, and he could not draw a picture from memory, even immedi- 
ately after he copied it. Franklin et al. [21, p. 182] reported a similar patient, $\mathrm{MH}$, a 77-year-old woman. Her characteristic impairment was an inability to draw an object from memory and superior ability in drawing from objects that were present. Her drawing was much better when the object was a 3-dimensional real object or a realistic picture, rather than line drawings. In addition, she also exhibited deterioration of a visual semantic ability described as 'a central semantic impairment'. Thus, differences in painting styles between the patients in cases 1 and 2 may reflect the nature of their deficits. When the deficit was restricted to word meaning, the patient could draw a picture from memory. In contrast, when the deficit was more global (visual semantic or central semantic impairment), the patient could not draw a picture from memory, but could draw present scenes and objects.
Few patients have leisure activities after the onset of dementia. However, our patients started painting following their caregiver's or clinician's suggestion and enjoyed these activities for a long period. These activities might serve as emotional support not only for patients, but also for their families. This observation also means that for the clinician or caregiver, it might be important to be aware of a patient's intact functions to gauge the patient's quality of life.

\section{Acknowledgments}

This study was supported by CREST and a Grant-in-Aid for Scientific Research on Priority Areas - System Study on HigherOrder Brain Functions from MEXT (M.K.). This study was also supported in part by a Chuo University Grant for Special Research (A.M.).

\section{References}

1 Grabowski TJ, Damasio AR: Definition, clinical features and neuroanatomical basis of dementia; in Esiri MM, Lee VMY, Trojanowski JQ (eds): The Neuropathology of Dementia, ed 2. Cambridge, Cambridge University Press, 2004, pp 1-33.

$>2$ Miller BL, Cummings J, Mishkin F, Boone K, Prince F, Ponton M, Cotman C: Emergence of artistic talent in frontotemporal dementia. Neurology 1998;51:978-982.

$\checkmark 3$ Drago V, Foster PS, Trifiletti D, FitzGerald DB, Kluger BM, Crucian GP, Heilman KM: What's inside the art? The influence of frontotemporal dementia in art production. Neurology 2006;67:1285-1287.

4 Mell JC, Howard SM, Miller BL: Art and the brain: the influence of frontotemporal dementia on an accomplished artist. Neurology 2003;60:1707-1710.

5 Tanabe H, Nakagawa Y, Ikeda M, Hashimoto M, Yamada N, Kazui H, Nishikawa T, Okuda JI: Selective loss of semantic memory for words; in Ishikawa K, McGaugh JL, Sakata H (eds): Brain Processes and Memory. Amsterdam, Elsevier, 1996, pp 141-152.

6 Snowden J, Neary D, Mann D: Fronto-Temporal Lobar Degeneration: Fronto-Temporal Dementia, Progressive Aphasia, Semantic Dementia (CNNM). New York, Churchhill Livingstone, 1996.
7 Shinagawa F, Kobayashi S, Fujita K, Maekawa H: Japanese Wechsler Adult Intelligence Scale-Revised. Tokyo, Nihon Bunka Kagakusya, 1990.

8 Raven J: The Coloured Progressive Matrices Test. London, Lewis, 1965.

9 Heaton R, Chelune G, Talley J, Kay G, Curtiss G: Wisconsin Card Sorting Test Manual. Odessa, Psychological Assessment Resources, 1993.

10 Kertesz A: The Western Aphasia Battery (in Japanese). Tokyo, Igaku-shoin, 1986.

11 Katoh S, Shimogaki H, Onodera A, Ueda H, Oikawa K, Ikeda K, Kosaka A, Imai Y, Hasegawa K: Development of the revised version of Hasegawa's Dementia Scale (HDSR). Jpn J Geriatr Psychiatry 1991;2:13391347.

12 Folstein MF, Folstein SE, McHugh PR: 'MiniMental State': a practical method for grading the cognitive state of patients for the clinician. J Psychiatr Res 1975;12:189-198.

13 SLTA Committee: Standard Language Test of Aphasia: Manual of Directions, ed 2. Tokyo, Homeido, 1977.

14 Tanabe H, Ikeda M, Nakagawa Y, Yamamoto H, Ikejiri Y, Kazui H, Hashikawa K, Harada K: Gogi (word meaning) aphasia and semantic memory for words. High Brain Funct Res 1992;12:153-167.

15 Miller BL, Boone K, Cummings JL, Read SL, Mishkin F: Functional correlates of musical and visual ability in frontotemporal dementia. Br J Psychiatry 2000;176:458-463.
16 Kapur N: Paradoxical functional facilitation in brain-behaviour research: a critical review. Brain 1996;119(pt 5):1775-1790.

17 Heilman KM, Nadeau SE, Beversdorf DO: Creative innovation: possible brain mechanisms. Neurocase 2003;9:369-379.

18 Gordon N: Unexpected development of artistic talents. Postgrad Med J 2005;81:753755.

19 Selfe L: Nadia: A Case of Extraordinary Drawing Ability in an Autistic Child. London, Academic Press, 1977.

20 Chatterjee A: The neuropsychology of visual artistic production. Neuropsychologia 2004; 42:1568-1583.

21 Franklin S, van Sommers P, Howard D: Drawing without meaning? Dissociations in the graphic performance of an agnosic artist; in Campbell R (ed): Mental Lives: Case Studies in Cognition. Oxford, Blackwell, 1987.

22 Happé FG: Wechsler IQ profile and theory of mind in autism: a research note. J Child Psychol Psychiatry 1994;35:1461-1471.

23 Shah A, Frith U: Why do autistic individuals show superior performance on the block design task? J Child Psychol Psychiatry 1993; 34:1351-1364.

24 Hermelin B, Pring L, Heavey L: Visual and motor functions in graphically gifted savants. Psychol Med 1994;24:673-680. 